of these cases. Although the anterior cells were engorged, the middle tmbinal pressing tightly against the septum, yet in neither case was there any indication of the antrum of Highmore being affected.

\title{
TWO POINTS IN THE DEVELOPMENT OF THE MIDDLE EAR AND ITS CONTENTS.
}

By Mr. Thomas Guthrie, M.A., M.B., B.C.Cantab., F.R.C.S.Eng., Aurist and Laryngologist to the Victoria Central Hospital, Liscard.

Altholgh known to Fabricius the processus longus or gracilis of the malleus has been especially associated with the name of $C$. Folius, who lived in the first half of the seventeenth century. After him it is known as the Folian process. He described, howerer, only the small remains of the process in the adult, and the long, slender, bony rod which is found in the newly born was first lescribed by the German anatomist Ravius.

The connection, in the early stages of development, of the Iroximal end of Meckel's cartilage with the head of the malleus is well known, and on the authority of Reichert, Parker, Balfour, and whers it has been stated that during the later stages of fotal life, While the distal part of Neckel's cartilage atrophies and disappears, the proximal portion ossifies and persists as the processus longus of the malleus. This view of the origin of the processus longus ippears to have gained very general acceptance in this country. In the other hand, Meckel himself stated that the process arose as :u independent membrane bone, and his observations liave been - apported by other anatomists, and notably by Broman, who made i? detailed study of the development of the auditory ossicles.

The writer has investigated the matter chiefly by means of serial microscope sections of temporal bones at a number of lifferent stages of fœetal life, and has reached the following conclusions: The Folian "process" is at first quite separate from the mallens. It appears at about the end of the second month of fretal life as a rod-shaped membrane bone, which lies below and slightly internal to the proximal part of Meckel's cartilage. At this age the malleus is entirely cartilaginous. The proximal end of the rod does not at first reach the malleus, but later becomes applied to it about the region of the neck, at which point ossification is proceeding. Finally, direct bony union takes place between the "process" and the malleus. 
Meckel's cartilage is at first attached to quite the upper part of the malleus. Owing, however, to the relatively rapid growth

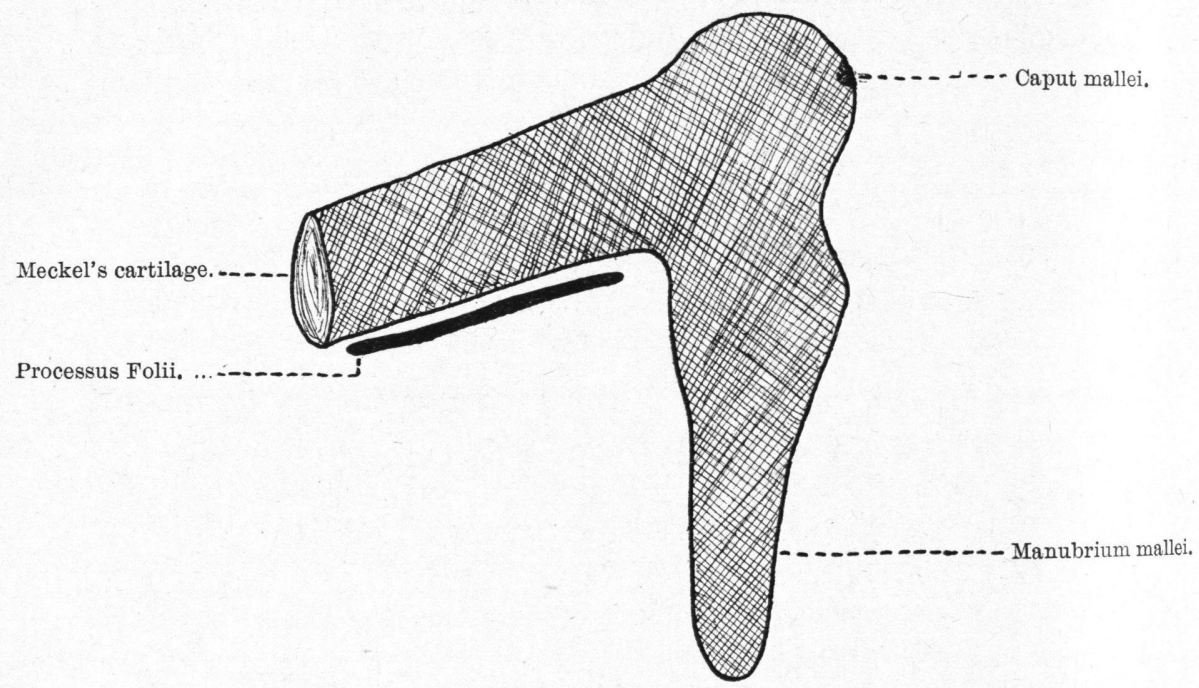

FiG. 1.- Malleus and Folian process at about two and a half months of foetal life.

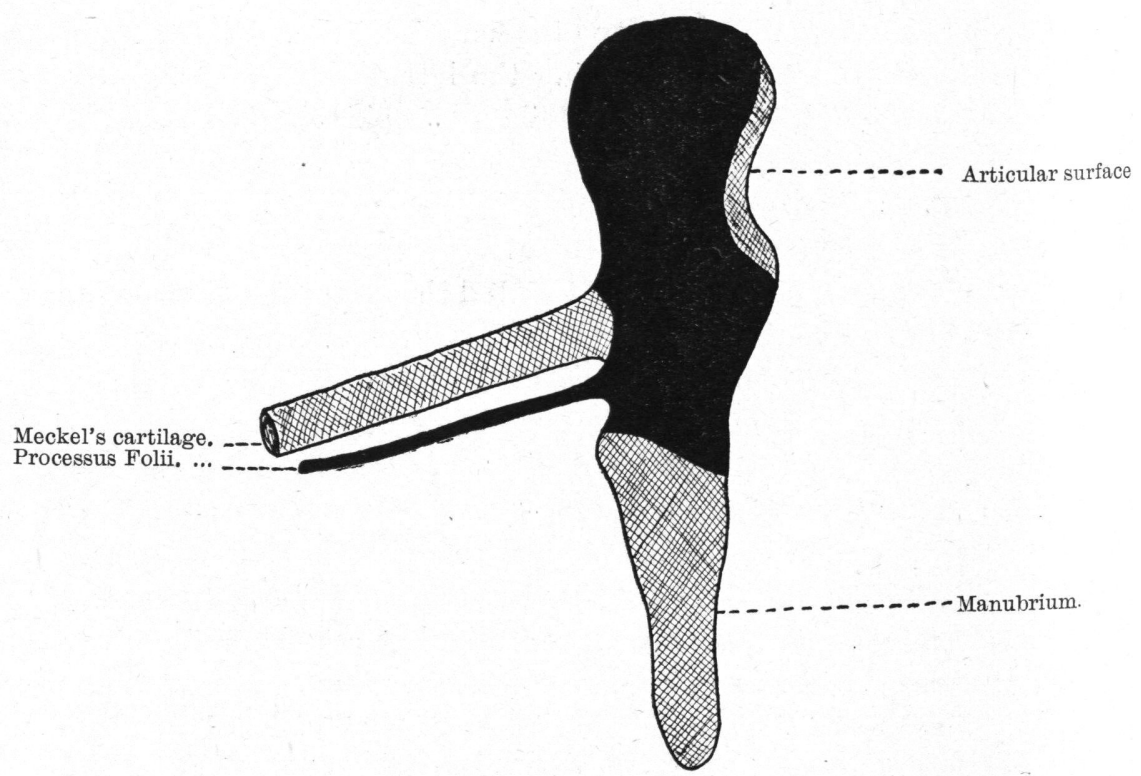

Fia. 2.-Malleus at about six months of foetal life. (Bone is represented black, cartilage by cross-hatching.)

of the head of the malleus the point of attachment of the cartilage appears to pass downwards and eventually to reach the neck. 
Towards the end of fotal life this proximal part of Meckel's cartilage becomes shrunken and atrophied, and eventually is incorporated in the anterior ligament of the malleus and lost. No part of it undergoes ossification. The Folian process, on the other hand, is well developed, and forms an important feature of the malleus

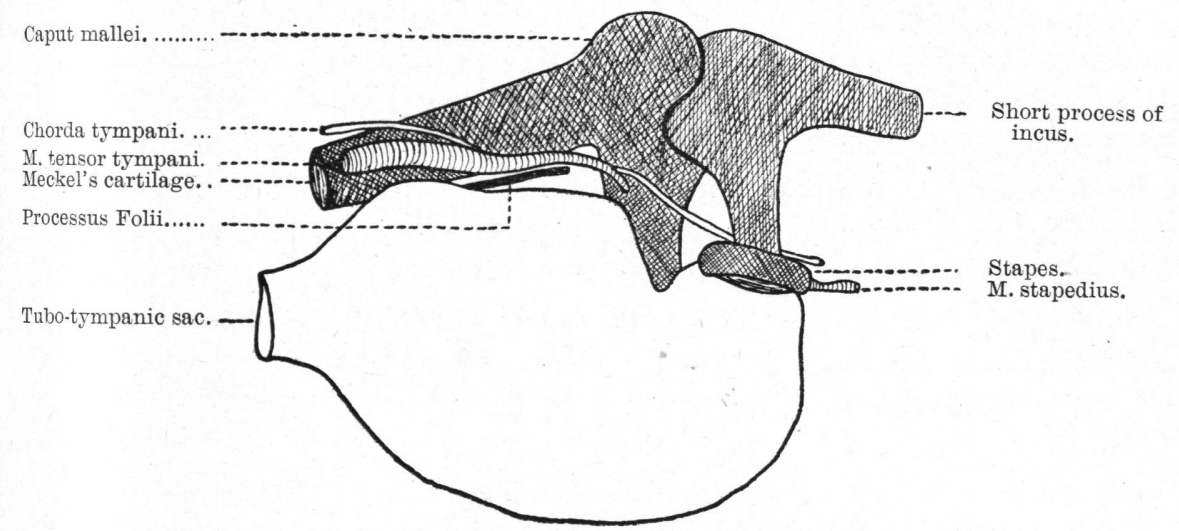

FIG. 3,-The tubo-tympanic sac and auditory ossicles at about two and a half months of foetal life.

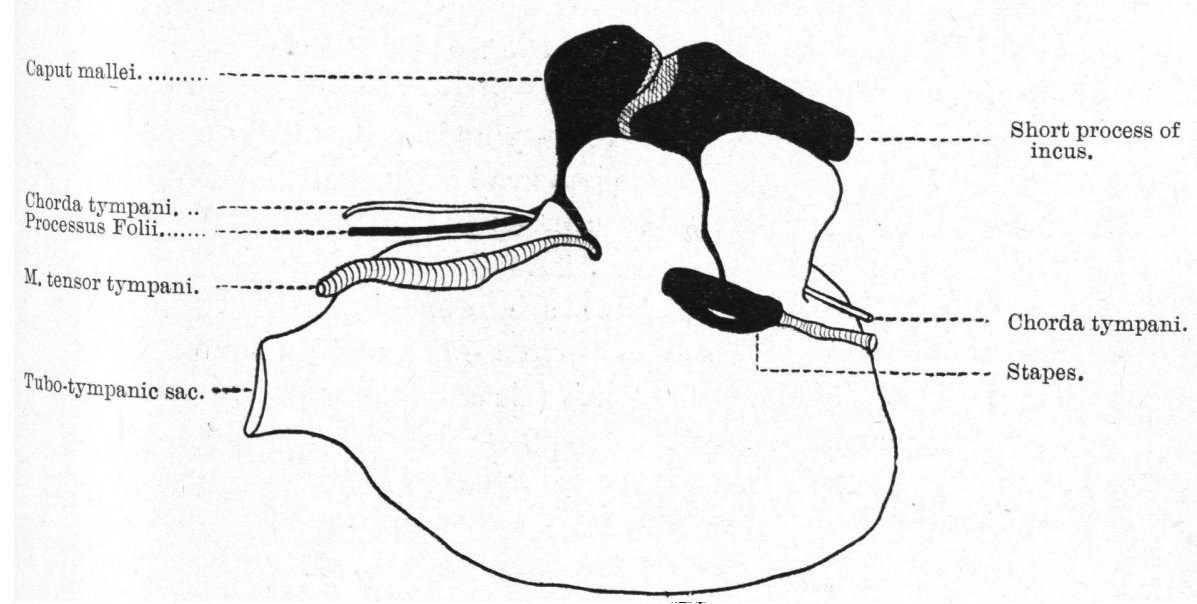

Fra. 4.-The tubo-tympanic sac and auditory ossicles at about six months of fotal life. (Bone is represented black, cartilage by cross-hatching.)

during the second half of fœetal life and for a considerable time afterwards. In the adult, however, the process is found to have largely disappeared and to be represented only by a small projection on the anterior border of the neck of the malleus.

Morphologically the process is interesting, as it certainly represents one of the membrane bones which ensheath Meckel's 
cartilage in most of the lower vertebrates. Its vestigial charactel is indicated by its almost total absence in the adult.

Some confusion has been manifested as to the process by which the cavity of the middle ear is developed at the expense of the embryonic gelatinous tissue, which at first fills the greater part of the middle-ear cleft. ${ }^{1}$ In early fotal life the tubo-tympanic cavity extends only to quite the lower part of the tympanum, the remainder of the middle-ear cleft being occupied by gelatinous tissue. As development proceeds the cavity gradually enlarges. A pouch passes up between the handle of the malleus and the long process ot the incus. This pouch later gives off two pockets, one of which passes up behind and one in front of the head of the stapes, while a third diverticulum from the main sac passes up in front of the tendon of the tensor tympani muscle. Finally, as the walls of the sac become applied to the walls of the middle-ear cleft several other pouches and recesses appear, such as the recess of the fenestria rotunda and the recess of the sinus tympani. A large diverticulum also passes backwards and upwards and fills the antrum.

Althongh at the end of fœtal life there are still remnants of the gelatinous tissue, especially about the antrum, most of it has at thiagre disappeared so that the walls of the middle-ear cleft are lintert by mucous membrane.

The growth, therefore, of the tubo-tympanic sac at the expense of the embryonic gelatinous tissue is a gradual one, and begins quite early in fœtal life, but proceeds more rapidly during the later than the earlier stages of development. At the end of fœtal life only remnants of the gelatinous tissue are present in the shape if localised thickenings of the mucous membrane, and at this age the? mucous lining of the middle-ear cleft (Eustachian tube, tympanum, and antrum) is complete.

1 By " middle-ear cleft" is meant the space bounded by the cartilaginous ant $t$ bony walls of the Eustachian tube, tympanum, and antrum.

New Works.-'I'wo recent additions to the literature of onr specialty have been forwarded to us by the publisher, Alfrel Holder, of Vienna and Leipzig. The one on "The Brain and the Accessory Sinuses of the Nose" "Das Gehirn und die Nebenhöhlen der Nase) is from the pen of Professor Onodi, of BudaPesth; the other, by Dr. H. E. Kanasugi, consists of "Contributions to the Topographico-Chirurgical Anatomy of the Mastoil Region" ("Beiträge zur Topographisch-Chirurgischen Anatomie" der Pars Mastoidea"). 